\title{
Intention Factors of Adoption Halalan Toyyiban Risk Management Plan: Between Technology, Organizational, Environment and Halal Awareness as Mediator
}

\author{
NURSHAHIRAH SALEH \\ University of Technology Mara Shah Alam, Selangor. Malaysia. \\ Email: nurshahirahsaleh@gmail.com \\ IRWAN IBRAHIM \\ University of Technology Mara Shah Alam, Selangor. Malaysia.
}

\begin{abstract}
The purpose of this paper is to answer the relationship between technology, organization, and environment, and the intention factors to adopt Halalan Toyyiban Risk Management Plan (HTRMP). The strongest factor will come out from this research which supports the intention to adopt halalan toyyiban risk management plan among food manufacturers SMEs in Malaysia. 120 samples of halal food manufacturer SMEs in Malaysia was used. The method used is a quantitative approach and using SEM-PLS to analyse the scientific data. The hypothesis of this research is to find the relationship between technology, organization, and environment and intention to adopt HTRMP, halal awareness as mediator. The results find that there are four positive relationships which were compatibility in technology, Organisational readiness and expected business benefit in the Organisation, and halal market in the environment are four criteria that have a favorable link with the intention adopt HTRMP. Compatibility also found as the most influential determinant for HTRMP adoption among food manufacturers SMEs. The data were collected during halal food events, Halal Festival (Halfest) and Selangor International Business Summit in Malaysia. The sample size is small. Findings can supervise the authority in successfully enhancing the application of HTRMP among food manufacturers in Malaysia. The food manufacturer can comply HTRMP accordingly with its benefit. The benefit of this research is to improvise the application of HTRMP among food manufacturers in Malaysia to increase and maintain the quality, safety and halal of their food products. Due to that HTRMP is lack study in halal management research from the previous journal.
\end{abstract}

Keywords: Halal Management, Technology factors, Organization factors, Environment Factors, Mediator, SEM-PLS.

\section{Introduction}

According to the HDC (2016) database, halal SMEs include around 5,700 halal manufacturers and 1,158 food and beverage companies. To control the quality, halal, and safety of food commodities, the halalantoyyiban component is critical throughout the full chain of product movement (Yahya et al., 2016). Muslims should pay attention to the original halal logo on items and should not be afraid to consume it because it guarantees the product's quality, hygiene, and cleanliness (Aziz \& Sulaiman, 2014).

The HTRMP ensures the quality, safety, and halal toyyiban of products from farm to fork, making it an important part of food management. A successful operator in this business needs to implement the Halal Toyiban Risk Management Plan (HTRMP) to assure halal quality. The halal quality will improve and contamination will be avoided if Malaysian SMEs employ HTRMP throughout their process and supply chain flow till it reaches the client (Azmi et al., 2018). Additional study on HTRMP is also required due to 
a lack of references from previous studies.

Malaysia Standard 2400-1:2010 requires each halal-certified company to create a Halal Toyyiban Risk Management Plan (HTRMP) based on the standard in order to control the halal, quality, and safety of the product (Yahya et al., 2016). All halal food makers should take responsibility for learning about the importance and necessity of applying HTRMP in their management after acquiring the halal certificate. The difficulty is that only $15 \%$ of food producers apply the halal standard as a new system in their halal food company management, forcing them to adapt to a variety of food quality standards methods (Azmi et al., 2019).

To determine whether food producers intend to apply HTRMP, the components of the technology, organisation, and environment (TOE) framework were used. Technology, organisational structure, and environmental factors are all evaluated using the TOE paradigm. The local government is critical in monitoring and educating food producers about the need of following the halal toyyiban supply chain.

Ngah et al., (2014) discovered that drivers of adoption such as perceived advantage could be a driver of adoption for future study because they recognise the value for their firm to apply using the theory of technology, organisation, and environmental variables (TOE framework). In a recent study by Ngah et al., (2017) customer pressure, organisational readiness, and perceived benefits were found to influence the intention to embrace halal warehousing services, and those qualities were recognised as the drivers of adoption in halal warehouses. The purpose of this research is to look at the factors that influence management's decision to implement the HTRMP in their process chain. Halalan toyyiban services must successfully manage all vital points of halal status, including documenting the hazard for other workers or management to assess. In addition, the food industry must keep track of the halal status of halal products and services. This study will fill a research gap in the field of organisation adoption from the perspective of the management unit in food manufacturing SMEs that are implementing HTRMP based on these findings.

\section{Literature Review}

\section{Introduction of Halal Toyyiban Risk Management Plan (HTRMP)}

The Halalan-toyyiban Risk Management Plan (HTRMP) is one of the approaches specified in Malaysia Standard 2400-1:2010, in which risk variables at Halalan-toyyiban critical control points (HTCCP) are monitored and control mechanisms for preserving halal, safety, and quality are implemented (Yahya et al., 2016). HTRMP is used as a guideline to prevent, eliminate, or decrease contaminant and non-toyyiban precursor-affected products to an acceptable level.

From the beginning to the end of processes related to goods and cargo transportation chains activities, the scope determines the processes and locations of processes/activities that are covered by the system:

1. Ensure that the policy is relevant to and in compliance with halalan - toyyiban requirements;

2. Confirm that the policy in relation to the halalan - toyyiban objective is understood, implemented, and maintained at all levels of the organisation;

3. Review the results of the risk management activities at defined intervals to ensure the risk management activities' continued suitability and effectiveness;

4. Ensure that the proper communication processes are used both inside and outside the firm to ensure the halalan - toyyiban management system's performance.

Two previous investigations (Samicho et al., 2016) discovered the halal toyyiban component, and (Yahya et al., 2016) issued a recommendation on employing HTRMP in a frozen food cold storage. According to their findings, constructing HTRMP is vital and required for the organisation to maintain the halal and 
toyyiban status of food goods. The study case reveals a research gap among food makers, which is significant given that this industry accounts for roughly half of Malaysia's food output (Azmi et al., 2019).

\section{Technology, organization, and environment (TOE) Factors}

According to Oliveira and Martins (2011), the Technology Acceptance Model (TAM), Theory of Planned Behaviour (TPB), and Unified Theory of Acceptance (UTAUT) measure individual behaviour, whereas the Technology, Organization, And Environment (TOE) framework (Tornatzky et al., 1990) and Diffusion On Innovation (DOI) (Rogers, 1995) measure firm behaviour. DOI is a theory that describes what factors influence a person's decision to embrace and use a new technology (Oliveira \& Martins, 2011). It examines how, why, and how quickly new ideas and technologies spread across cultures (Mohammed et al., 2016; Rogers, 2002).

DOI's theory is strong because it gives a broad foundation for understanding the factors that influence an individual's decision to adopt new technology, and it is the foundation for understanding adoption (Straub, 2009). Meanwhile, TOE identifies three influences on innovation adoption: technological context, organisational context, and environmental context (Mohammed et al., 2016; Oliveira and Martins, 2011; Baker, 2012). Adoption theories are primarily focused with identifying, characterising, or forecasting why, how, and to what extent practitioners would adapt and change their behavioural processes or accept contemporary technologies (Hameed et al., 2012).

In the Halal context, environmental issues, such as government involvement in Halal implementation, become critical considerations. Previous research has revealed the most influential factors in the government's support of Halal standards (Tan et al., 2012; Zailani et. al., 2015). Furthermore, governmentrelated aspects play an important role in removing major roadblocks and establishing a Halal environment (Ngah et al., 2014; Iskandar et al., 2012). Because the environment is one of the variables to be explored in this study, researchers frequently use the TOE framework, which is nearly identical to the DOI framework.

Because it gives key theoretical insights, this paradigm is valuable for studying contextual aspects (Tornatzky et al., 1990; Baker, 2012). The TOE framework divides innovation adoption into three structure groups: technological context, organisational context, and environmental context (Mohammed et al., 2016). Furthermore, Azmi et al., (2018) identified technology compatibility and perceived benefits, organisational context, halal integrity, halal awareness, anticipated economic benefits, and organisational readiness as halal standards adoption factors in Malaysian practises.

Meanwhile, in the environmental context, government support, competition pressure, consumer pressure, and market orientation are all issues. In 2018, Musa et al. conducted research on the impact of the halal food supply chain on food production performance, and discovered that perceived benefit was the driving force behind technology adoption. The environmental context was driven by the halal market, whereas the organisational context was driven by readiness.

The three areas of Halal standards adoption for halal food manufactures, according to Azmi et al., (2018), are technological, organisational, and environmental. While compatibility and perceived benefits play a role in technology adoption, top management support, organisational readiness, understanding practices, expected business benefit, and halal integrity play a role in organisational adoption. The five environmental variables include government support, competitor pressure, consumer pressure, and halal market. This study will fill a research gap in the field of organisational adoption from the perspective of the management unit in food manufacturing SMEs utilising HTRMP based on these findings. 
Table 1: The finding of TOE context towards halal from the previous study

\begin{tabular}{|c|c|c|c|}
\hline Researcher & Ngah et al. & Musa \& Azmi & Azmi et al. \\
\hline Year & 2017 & 2018 & 2018 \\
\hline Industry & Halal warehouse & Food manufacturing & Malaysian manufacturer \\
\hline $\begin{array}{l}\text { Technology } \\
\text { Context(driven } \\
\text { value) }\end{array}$ & Perceived benefit & Perceived benefit & $\begin{array}{ll}\text { compatibility } & \text { and } \\
\text { perceived benefits } & \end{array}$ \\
\hline $\begin{array}{l}\text { Organizational } \\
\text { Context(driven } \\
\text { value) }\end{array}$ & $\begin{array}{l}\text { Organizational } \\
\text { readiness as driven } \\
\text { value }\end{array}$ & Organizational readiness & $\begin{array}{l}\text { supporting management, } \\
\text { halal integrity, halal } \\
\text { awareness, expected } \\
\text { business benefits, and } \\
\text { organizational readiness }\end{array}$ \\
\hline $\begin{array}{l}\text { Environment } \\
\text { Context (driven } \\
\text { value) }\end{array}$ & $\begin{array}{l}\text { Customer pressure as } \\
\text { driven value }\end{array}$ & Halal market & $\begin{array}{l}\text { Government support, } \\
\text { competitive pressure, } \\
\text { consumer pressure, and } \\
\text { halal market demand }\end{array}$ \\
\hline
\end{tabular}

\section{Theoretical Framework}

To acquire an overview of the driving forces of Halal standards, this study conducted literature searches on the topics of Halal adoption studies using databases such as Science Direct, Emerald, ProQuest, and Google Scholars, among others. This study investigates the factors that influence HTRMP adoption among Malaysian food manufacturing SMEs in terms of technology, organisation, and environment.

\section{Technological Factors}

Premkumar (2003) claims that only a few research has looked at the impact of technology aspects in the context of small businesses. Technological factors refer to creative traits in some studies of organisational adoption (Premkumar and Roberts, 1999). As a factor influencing technology adoption, perceived benefits, compatibility, complexity, and cost have all been considered (Ranganathan and Jha, 2005; Sharma and Citurs, 2005). When selecting whether or not to adopt, perceived benefits and compatibility are crucial considerations (Tan et al., 2012; Ngah et al., 2014). Premkumar (2003) claims that compatibility is a significant aspect in management innovation adoption. Compatibility is defined as the degree to which it is perceived to be consistent with existing values, experience, and potential adopter needs (Rogers, 2002).

A company tries to incorporate new ideas that are compatible with its operations, processes, and activities (Musa et al., 2016). In this setting, existing technology is constant in producing Halal foods and conducting regular business operations. In order to ensure its long-term profitability, the corporation also feels that a new technology (potential adopter) is required. The standard agency determines the requirements that firms must meet. As a result, perceived technology benefits businesses in terms of operational management (receiving, processing and handling, storage, and delivery). However, it should be examined in terms of the company's ability to adapt new technology as well as the necessity to do so. ICT use in Halal transportation, according to Tan et al. (2012), allows them to obtain and provide information as well as communicate with immediate suppliers or customers. Furthermore, compatibility issues will occur if various consumers or businesses use different systems, resulting in inconsistency (Talib et al., 2014). As a result, the following is the compatibility hypothesis:

\section{H1: Compatibility has positive, significant relationship with the adoption of HTRMP}

Perceived benefits refers to the extent to which new technologies provide more benefits than older ones (Lin and Lin, 2008). The ability of an organisation to adopt innovations is dictated by its members' abilities, its ability to give training for developing these talents, or the acquisition of experienced personnel, 
according to Musa et al. (2016). Ngah et al. (2014b) defined perceived benefits as the extent to which management perceives the relative benefit that Halal supply chain services can provide to enterprises. The implementation of a halal food supply chain was influenced by the technical environment. The best predictor of technology adoption is perceived advantages. Therefore, the hypothesis for perceived benefit is as follows:

H2: Perceived benefit has a positive, significant relationship with the adoption of HTRMP

\section{Organizational Factors}

As a result, the researchers believe that organisational knowledge, encouragement, and planning could influence creativity (Iskandar et al., 2012). Expected commercial benefits, ethics, top management support, and knowledge of new procedures are all factors that contribute to increased innovation (Zailani et al., 2015; Ngah et al., 2010). Top management support has been included as a variable in adoption studies by Ahmed et al., 2016; Diánez-González and Camelo-Ordaz, 2016; Musa, 2014; Musa et al., 2016; QuintanaGarca and Benavides-Velasco, 2016; Winter and Lasch, 2016. Top management involvement in the adoption of a new operation is critical in terms of generating support in terms of bot resources.In addition to advocating changes for the organization's benefit, top management could drive adjustments to accept new technologies in their company operations (Ngah et al., 2010). Therefore, the hypothesis for the top management is as follows:

H3: Top management support has positive, significant relationship with the adoption of HTRMP

The internal traits and assets of a corporation, as well as the type of new technology to be applied, are all factors in organisational preparedness (Tarmizi et al., 2014). (Abdul Hafaz et al., 2014) define organisational preparedness as operational management's ability to accept Halal transportation services in terms of financial and human resources. Furthermore, in a study on halal food supply chain adoption among food manufacturers SMEs, Azmi et al. (2018a) discovered that organisational readiness improves business performance. The existence of an external and internal information system that allows the Halal industry to develop a customer and partner relationship management mechanism is this component (Tan et al., 2012). As a result, the following is the organisational readiness hypothesis:

H4: Organizational readiness has positive, significant relationship with the adoption of HTRMP

Halal food manufacturers' motivation to adopt the HTRMP will be based on their knowledge of Halal procedures. Academics must first identify the facilitators and obstructions in order to grasp the genuine situation that occurs in the Halal industry and ultimately provide information about the industry to the government (Ngah et al., 2014). Food manufacturers are still failing to implement the HTRMP system in organisational management to control the risk of non-halal contamination during warehousing, according to a review by (Yahya et al., 2016). Participants must not only meet existing standards in terms of food security, but also understand Shariah law to ensure that the implementation is successful. Halal food makers must understand and follow these regulations in order to maintain their Halal designation (Halal Industry Development Corporation, 2010). According to Alserhan (2016), evaluating whether a product is Halal or not takes place at the end of the manufacturing process, when the procedure and ingredients are guaranteed to meet Islamic Shariah criteria. As a result, the following is the hypothesis for comprehending the practise:

H5: Understanding the practice has positive, significant relationship with the adoption of HTRMP

Halal Integrity refers to things that are still Halal from upstream to downstream in the supply chain, free of any activity that could, intentionally or unintentionally, contradict Halal certification (Mohamed et al., 2016). In this context, the implementation must meet the requirements of the standards from the raw 
materials to the final consumption. Receiving raw materials (ingredients) and packaging materials, for example, are critical steps in preserving the integrity and wholesomeness of Halal cuisine (Halal Industry Development Corporation, 2010). Alserhan (2016) claims that Halal integrity ensures that strong relationships with partners are required to ensure that each product is Halal. Consumers have high expectations for halal products in terms of quality and assurance, and halal integrity must never be jeopardised (Harlina et. al., 2012). As a result, it is thought that those who are truthful have a stronger willingness to use halal business practises (Soltanian et al., 2016). Halal integrity leads to more complete Halal standards, more efficient Halal certification, and increased Halal awareness. As a result, the following is the Halal integrity hypothesis:

H6: Halal integrity has positive, significant relationship with the adoption of HTRMP

In the context of this review, the degree of Halal acceptance is forecasted in terms of consumer return. Businesses' principal purpose is to make money. Malaysians are a Muslim community that understands what it means to be Halal. According to Suki and Salleh, the Halal images displayed by merchants' influence consumers' purchasing decisions (2016). Non-Muslim customers have a positive influence on the inclination to buy Halal products (Aziz and Chok, 2013). If Halal procedures are applied with satisfactory results, firms will have a successful competitive performance. Firms will be incentivized to embrace Halal standards if they gather knowledge for business purposes. As a result, the theory

H7: Expected business benefit has positive, significant relationship with the adoption of HTRMP

\section{Environmental Factors}

According to Lertwongsatien and Wongpinunwatana, the environment is regarded in the innovation literature as an influential component in an organization's adoption of innovation (2003). Pressures from customers and rivals, government support, and market orientation are all factors that impact the adoption of innovation in Halal environments (Zailani et al., 2015; Iskandar et al., 2012; Ngah et al., 2014b). Malaysia's food manufacturing industry has experienced various transformations, improvements, and repositioning during the last few decades (Siaw and Rani, 2012). As a result, it is believed that government support will encourage Halal manufacturers to adopt Halal criteria. Government support is critical in this scenario since government initiatives will urge firms to adopt Halal practises. The more government support granted, the more likely Malaysian Halal logistic service companies will adopt the new technology (Tan et al., 2012a). Therefore, the hypothesis for government support is as follows:

H8: Government support has positive, significant relationship with the adoption of HTRMP

Competitive pressure becomes more crucial to the firm's behaviour, according to Kraus et al. (2012). Ngah et al. (2014b) describe competitive pressure as "pressure that emerges from the risk of losing a competitive advantage, forcing firms to adopt and distribute Halal supply chain services." Businesses may feel driven to innovate in order to obtain a competitive advantage as market competition rises (Wang et. al., 2010). Competitive pressure, according to Mohiyaddin (2006), has no significant impact on Halal food producers' desire to be certified as Halal Standard. Several local Chinese eateries are becoming Halal certified, according to Fischer (2016), in order to comply with Islamic law. Therefore, the hypothesis for competitive pressure is as follows:

H9: Competitive pressure has positively significant relationship with the adoption of HTRMP

Consumer pressure is a type of external pressure that might impact an adoption decision (Ngah et al., 2014b). In Muslim countries, consumer understanding of Halal allows them to seek out sanitary food that complies with Shariah law. The importance of religion in forecasting this attitude, according to Mukhtar and Butt (2012), can aid in satisfying the needs of Muslim clients. In addition, as Muslim consumers' 
understanding of their faith has improved, they have become choosier in the items and services they purchase or utilise (Zailani et al., 2015). In response to consumer demand, food producers, according to Talib et al. (2015), are committed to ensuring that commodities on the market are uncompromisingly Halal certified. As a result, the following is the consumer pressure hypothesis:

H10: Consumer pressure has positive, significant relationship with the adoption of HTRMP

The halal industry has a significant market demand. The emergence of Halal has made consumers think twice before using any product because it has been shown that Halal items may deliver greater quality (Pahim et al., 2012). The Islamic market's enormous size creates a tremendous demand for Islamic Branding (IB) expertise (Alserhan, 2010). The strongest predictor factor for firm performance in the halal food supply chain, according to (Azmi, Abdullah, Bakri, Musa, et al., 2018b), is halal market demand among food producers SMEs. To gain consumer trust, businesses must ensure that they adhere to Halal regulations, which can be accomplished through the adoption of Halal standards.

H11: Halal market demand has positive, significant relationship with the adoption of HTRMP

This investigation's mediating aspect is halal awareness. According to (Baron and Kenny (1986), a mediating factor is the third variable that explains the relationship between the independent variable (predictor) and the dependent variable (outcome). A mediator is a tool that enables a predictor to influence an outcome variable. In the context of Halal, awareness refers to having a specific interest in or experience with something, as well as being up to date on current advancements in Halal food, beverages, and products (Ambali and Bakar, 2013b).

We arrive at a theoretical mode after considering these hypotheses (Figure 1).

TECHNOLOGY

1. Compatibility,

2. Perceived benefits

\section{ORGANIZATION}

1. Management support

2. Organizational readiness

3. Understanding the practices

4. Expected business benefit and

5. Halal integrity

\section{ENVIRONMENT}

1. Government support

2. Competitive pressure,

3. Consumer pressure

4. Halal market demand
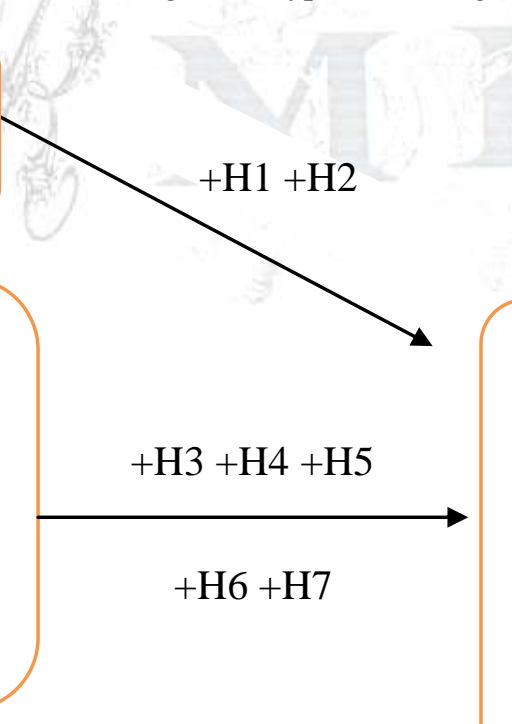

$$
+\mathrm{H} 6+\mathrm{H} 7
$$
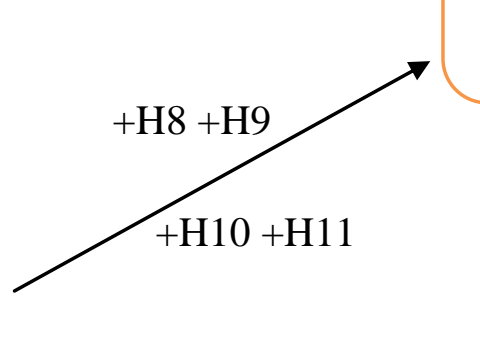

Figure 1: Theoretical Model
Intention to adopt Halal Toyyiban Risk Management Plan Among Food Manufactures SMEs 


\section{Results}

Our findings prove that there were four positive relationship hypotheses which are as below:

Table 2: Direct Relationship for hypothèses setting

\begin{tabular}{|c|c|c|c|c|c|c|c|c|c|}
\hline $\begin{array}{l}\text { Hypothe } \\
\text { sis }\end{array}$ & Relationship & $\begin{array}{l}\text { Std } \\
\text { beta }\end{array}$ & $\begin{array}{l}\text { Std } \\
\text { Error }\end{array}$ & $\begin{array}{l}{[\mathrm{t}} \\
\text { value }]^{\wedge}\end{array}$ & Results & $\mathrm{f}^{2}$ & $\mathrm{q}^{2}$ & $\begin{array}{l}95 \% \text { CI } \\
\text { LL }\end{array}$ & $\begin{array}{l}95 \% \text { CI } \\
\text { UL }\end{array}$ \\
\hline & & & & $2.768^{*}$ & & 0.10 & 0.02 & & \\
\hline \multirow[t]{2}{*}{$\mathrm{H} 1$} & Compatibility $->$ halal awareness & 0.281 & 0.099 & $*$ & Supported & 7 & 4 & 0.126 & 0.439 \\
\hline & Competitor pressure -> halal & & & & Not & 0.01 & 0.00 & & \\
\hline \multirow[t]{2}{*}{$\mathrm{H} 2$} & awareness & 0.07 & 0.116 & 0.59 & Supported & 0 & 0 & -0.122 & 0.257 \\
\hline & Consumers pressure $->$ halal & & & & Not & 0.02 & 0.00 & & \\
\hline \multirow[t]{2}{*}{$\mathrm{H} 3$} & awareness & 0.107 & 0.106 & 1.136 & Supported & 4 & 6 & -0.086 & 0.27 \\
\hline & Expected business benefits ->halal & & & & & 0.03 & 0.00 & & \\
\hline $\mathrm{H} 4$ & awareness & 0.174 & 0.112 & $1.68^{*}$ & Supported & 9 & 6 & -0.005 & 0.35 \\
\hline \multirow{3}{*}{ H5 } & Government support -> halal & & & & Not & 0.00 & $0.00^{-}$ & & \\
\hline & awareness & 0.024 & 0.075 & 0.333 & Supported & 0 & 2 & -0.098 & 0.159 \\
\hline & & & & & Not & 0.01 & 0.00 & & \\
\hline \multirow[t]{2}{*}{ H6 } & Halal integrity -> halal awareness & 0.091 & 0.103 & 0.891 & Supported & 0 & 2 & -0.072 & 0.255 \\
\hline & Halal market demand -> halal & & & & & 0.04 & 0.00 & & \\
\hline \multirow[t]{2}{*}{$\mathrm{H} 7$} & awareness & 0.173 & 0.089 & $1.875^{*}$ & Supported & 4 & 9 & 0.022 & 0.318 \\
\hline & Organizational readiness $->$ halal & & & $2.723 *$ & & 0.07 & 0.01 & & \\
\hline \multirow[t]{2}{*}{$\mathrm{H} 8$} & awareness & 0.267 & 0.099 & $*$ & Supported & 3 & 5 & 0.122 & 0.436 \\
\hline & Perceived benefit $->$ halal & - & & & Not & 0.00 & 0.00 & & \\
\hline \multirow[t]{2}{*}{ H9 } & awareness & 0.018 & 0.094 & 0.215 & Supported & 0 & 0 & -0.169 & 0.127 \\
\hline & Top management support $->$ halal & - & & & Not & 0.01 & 0.00 & & \\
\hline \multirow{2}{*}{ H10 } & awareness & 0.085 & 0.095 & 1.049 & Supported & 5 & 2 & -0.245 & 0.068 \\
\hline & Understanding practices $->$ halal & & & & Not & 0.01 & 0.00 & & \\
\hline H11 & awareness & 0.063 & 0.106 & 0.598 & Supported & 0 & 0 & -0.239 & 0.113 \\
\hline
\end{tabular}

$* * \mathrm{P}<0.1, * \mathrm{P}<0.05$

$* \mathrm{R}^{2}($ Awareness $=0.794, \mathrm{HTRMP}=0.454)$

*Effect size impact factor are according to Cohen (1988), $\mathrm{f}^{2}$ value $=0.35$ (large), 0.15(medium),0.02(small) $* \mathrm{Q}^{2}$ (Awareness $\left.=0.468, \mathrm{HTRMP}=0.301\right)$

*Predictive relevance $\left(\mathrm{q}^{2}\right)$ or Predictor Exogenous Latent variable as accordingly Henseler et al., (2009), $\mathrm{q}^{2}$ values :0.35(large), 0.15 (medium), and 0.02(small)

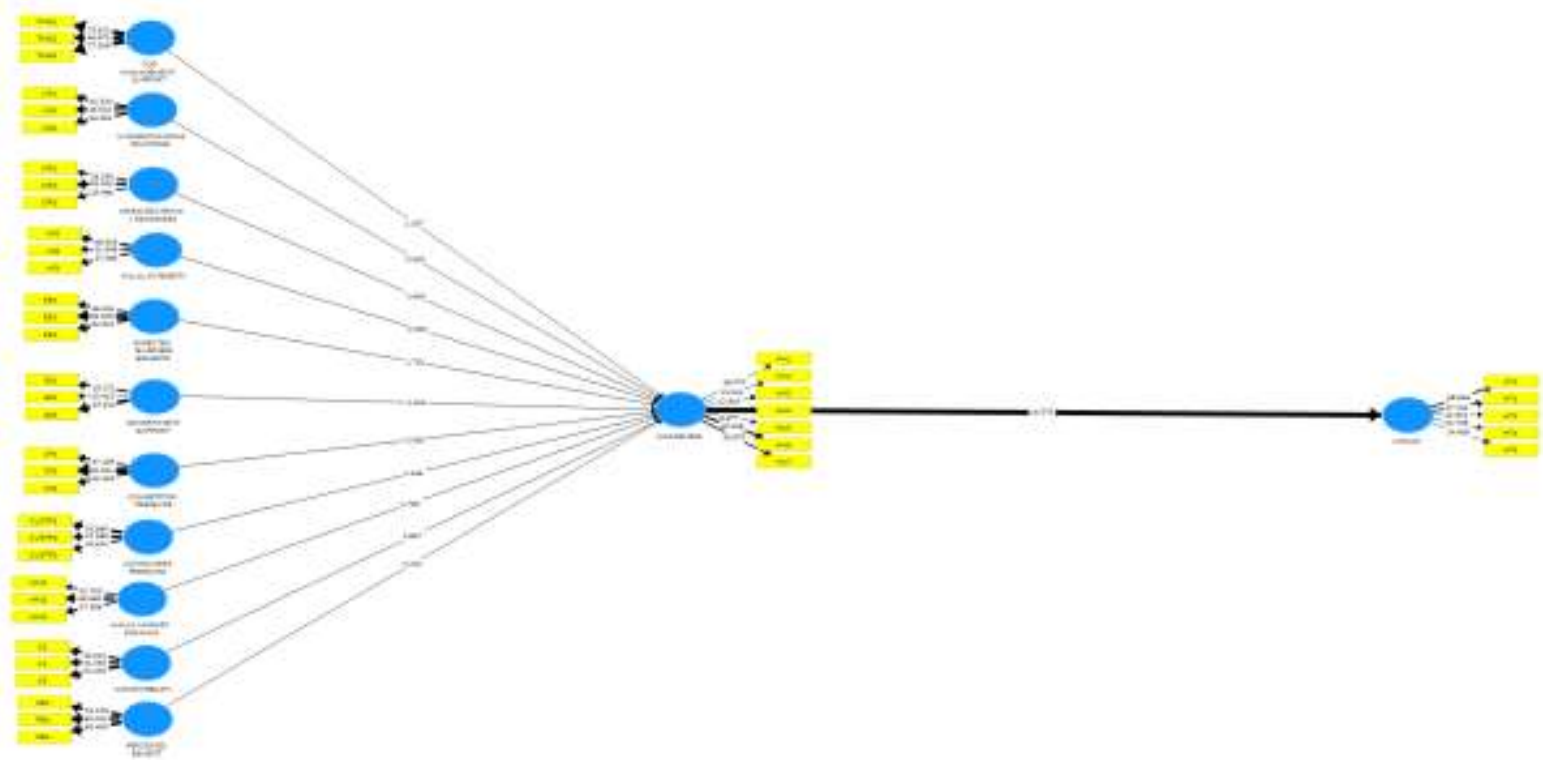


Table 3: Summary of Testing the Hypothesis

\begin{tabular}{|c|c|c|}
\hline HYPOTHESES & PROPOSED HYPOTHESIS & RESULTS \\
\hline $\mathrm{H} 1$ & $\begin{array}{l}\text { Compatibility has a positive relationship } \\
\text { with halal awareness in practice HTRMP }\end{array}$ & SUPPORTED \\
\hline $\mathrm{H} 2$ & $\begin{array}{l}\text { Perceived benefit has a positive relationship } \\
\text { with halal awareness in practice HTRMP }\end{array}$ & UNSUPPORTED \\
\hline $\mathrm{H} 3$ & $\begin{array}{l}\text { Top management support has a positive } \\
\text { relationship with halal awareness in practice } \\
\text { HTRMP }\end{array}$ & UNSUPPORTED \\
\hline $\mathrm{H} 4$ & $\begin{array}{l}\text { Organizational readiness has a positive } \\
\text { relationship with halal awareness in practice } \\
\text { HTRMP }\end{array}$ & SUPPORTED \\
\hline H5 & $\begin{array}{l}\text { Understanding practice has a positive } \\
\text { relationship with halal awareness in practice } \\
\text { HTRMP }\end{array}$ & UNSUPPORTED \\
\hline H6 & $\begin{array}{l}\text { Expected business benefit has a positive } \\
\text { relationship with halal awareness in practice } \\
\text { HTRMP }\end{array}$ & SUPPORTED \\
\hline & $\begin{array}{l}\text { Halal integrity has a positive relationship } \\
\text { with halal awareness in practice HTRMP }\end{array}$ & UNSUPPORTED \\
\hline & $\begin{array}{l}\text { Government support has a positive } \\
\text { relationship with halal awareness in practice } \\
\text { HTRMP }\end{array}$ & UNSUPPORTED \\
\hline & $\begin{array}{l}\text { Competitor pressure has a positive } \\
\text { relationship with halal awareness in practice }\end{array}$ & UNSUPPORTED \\
\hline H10 & $\begin{array}{l}\text { HTRMP } \\
\text { Consumer pressure has a positive }\end{array}$ & UNSUPPORTED \\
\hline & $\begin{array}{l}\text { relationship with halal awareness in practice } \\
\text { HTRMP }\end{array}$ & \\
\hline H11 & $\begin{array}{l}\text { Halal market demand has a positive } \\
\text { relationship with halal awareness in practice } \\
\text { HTRMP }\end{array}$ & SUPPORTED \\
\hline H12 & $\begin{array}{l}\text { Halal awareness as mediator has a positive } \\
\text { relationship with HTRMP }\end{array}$ & SUPPORTED \\
\hline
\end{tabular}

\section{Discussion and Conclusion}

According to the findings of the statistical analysis, four parameters have a positive relationship with the adoption of HTRMP: technological compatibility, organisational readiness and expected business benefit in organization, and halal market in the environment.

Because HTRMP is a big halal management breakthrough, compatibility in technology has a positive correlation with its acceptance. Compatibility was also discovered to be the most important factor of HTRMP adoption among SMEs in the food manufacturing industry. The Path Coefficient value $(=0.274)$ and probability (P 0.01) produced from the Path Coefficient study support this. This conclusion is corroborated by Tieman \& Che Ghazali (2014), who argue that for halal food handling, proper halal assurance systems for transportation, warehouse, and terminal are essential. Because HTRMP can control risk from the beginning of the process until it reaches the plate, it should be promoted among food manufacturers. HTRMP is halal-compatible, enabling for the documentation and implementation of a comprehensive halal risk management strategy throughout the food processing chain (Department of Standard Malaysia, 2010). 
The adoption of HTRMP was found to have two positive connections with organisational readiness and expected business benefit. According to the survey, organisational readiness may lead to HTRMP adoption because the firm has already trained its employees to comprehend HTRMP and management is ready to comply with and strategize their company using this halal management system. According to Tarmizi et al., internal traits and attributes of a firm are a factor inside the organisational readiness to adapt to new technologies (2014). The organisation is prepared to follow Halal guidelines in terms of finances and human resources (Ngah et al., 2017). The firm must also prepare in terms of training, planning, processes, and other variables in order to apply HTRMP in its halal management.

Because management recognises the added value of adhering to the HTRMP to their business, which includes the ability to sustain their business for a long time, provide more benefits to their business, and give their business a competitive advantage, the expected business benefit in the organisational factor has a positive impact on innovation. Every food firm wants to make a profit, and following the halal management system will provide them an advantage when the Muslim population expands to 2.2 billion by 2030 . The majority of Muslims in the study were worried about spreading the information about the advantages of halal eating. Malaysia's small and medium enterprises have a positive attitude toward the halal system because they regard the halal market as having a positive future influence (Azmi et al., 2018).

Because food producers aim to access the halal market, the halal market has a favourable relationship with HTRMP adoption, according to environmental considerations. The majority of food companies believe there is a high demand for halal food, that their product has a bright future, and that Muslim communities want and emphasise that their product be certified Halal by JAKIM in the Halal market, according to the survey. People are getting increasingly concerned about the Halal issue, according to an interview with a Halal Manager, and demand for Halal food and services is increasing (Tan et al., 2012). As the most important component of any halal manufacturer, the company must adopt and follow HTRMP as well as properly manage the product. Food manufacturers are embracing the halal system since the halal market demand for food is over 632 billion dollars in sales, which is equivalent to 16 percent of the world food sector.

\section{Limitations and Implications}

Despite various limits, the study of the importance of Halalan Toyyiban Risk Management Plan (HTRMP) will educate the government, business owners, and society in the design of halal sustainability strategies. Some of the limitations of this empirical study that should be made public in the future which is the constraint of questionnaire's dissemination, which is restricted to halal events in Selangor and Kuala Lumpur. However, because it is a national event, other states are welcome to participate. The future research can approach the organisation using the interview method to acquire a more in-depth examination. More research is needed to determine the validity of this study's findings, as longitudinal evidence may increase understanding of the causality and interrelationships between variables that are important for HTRMP adoption.

\section{Directions}

Halal food makers must employ technological improvements like the Halalan Toyyiban Risk Management Plan in order to maintain the halalness and quality of the meals. This study's findings have a variety of consequences for food producers who follow the HTRMP. In terms of organisational considerations, one of the most important factors in food producers' adoption of HTRMP is the expected commercial advantage. Consumer demand for halal cuisine is fuelling the growth of halal food producers. 


\section{References}

Aziz, N. A., \& Sulaiman, S. S. (2014). Role of the Local Authority in Issuing License for Halal Certified Premise in the City of Shah Alam. Procedia - Social and Behavioral Sciences, 121(September 2012), 133-143. https://doi.org/10.1016/j.sbspro.2014.01.1115

Azmi, F. R., Abdullah, A., Bakri, M. H., Musa, H., \& Jayakrishnan, M. (2018). The adoption of halal food supply chain towards the performance of food manufacturing in Malaysia. Management Science Letters, June, 755-766. https://doi.org/10.5267/j.msl.2018.5.0010

Azmi, F. R., Abdullah, A., Musa, H., \& Wan Mahmood, W. H. (2019). Perception of food manufacturers towards adoption of halal food supply chain in Malaysia: Exploratory factor analysis. Journal of Islamic Marketing, 11(3), 571-589. https://doi.org/10.1108/JIMA-12-2018-0236

Hair, J. F., Risher, J. J., Sarstedt, M., \& Ringle, C. M. (2019). When to use and how to report the results of PLS-SEM. European Business Review, 31(1), 2-24. https://doi.org/10.1108/EBR-11-2018-0203

Jr, H. F. H., Sartedt, M., Hopkins, L., \& Kuppelwieser, V. G. (2016). Partial least squares structural equation modeling ( PLS-SEM ) An emerging tool in business research. https://doi.org/10.1108/EBR10-2013-0128

Ngah, A. H., Zainuddin, Y., \& Thurasamy, R. (2014). Adoption of Halal Supply Chain among Malaysian Halal Manufacturers: An Exploratory Study. Procedia - Social and Behavioral Sciences, 129, 388395. https://doi.org/10.1016/j.sbspro.2014.03.692

Ngah, A. H., Zainuddin, Y., \& Thurasamy, R. (2017). Applying the TOE framework in the Halal warehouse adoption study. Journal of Islamic Accounting and Business Research, 8(2), 161-181. https://doi.org/10.1108/JIABR-04-2014-0014

Samicho, Z., Farhana, N., Karim, A., Firdaus, A., \& Azmi, M. N. (2016). Halalan Toyyiban Elements in Halalan-Toyyiban Risk Management Plan (HTRMP) of Chilled Food Products During Warehousing Activities: A Review. J. Appl. Environ. Biol. Sci, 6(11), 103-110. https://doi.org/6(11)103-110, 2016

Tan, M. I. I., Razali, R. N., \& Husny, Z. J. (2012). The adoption of Halal Transportations Technologies for Halal Logistics Service Providers in Malaysia. 6(3), 737-744.

Yahya, H., Samicho, Z., Firdaus, A., \& Nurul, M. (2016). A Review on Application of Halalan-Toyyiban Risk Management Plan ( HTRMP) and Frozen Food Chain during Warehousing Activities for Maintaining Halal, Safety, and Quality. Journal of Applied Enviromental and Biological Sciences, 6(11), 96-102. 